\title{
Helicobacter pylori serology in patients with coeliac disease and dermatitis herpetiformis
}

\author{
J E Crabtree, S O'Mahony, J I Wyatt, R V Heatley, J P Vestey, P D Howdle, \\ B J Rathbone, M S Losowsky
}

\begin{abstract}
Aims: To investigate whether Helicobacter pylori infection or autoimmune gastritis is responsible for the reported increase in gastric pathology and abnormalities of gastric function in patients with coeliac disease and dermatitis herpetiformis (DH).
\end{abstract}

Methods: Serum $H$ pylori IgG antibodies were assayed by enzyme linked immunosorbent assay and intrinsic factor antibodies by radioimmunoassay in 99 patients with coeliac disease and 58 patients with dermatitis herpetiformis from two geographic areas.

Results: $H$ pylori positivity in patients with coeliac disease and dermatitis herpetiformis increased with age, reaching $\mathbf{5 0 \%}$ and $70 \%$, respectively, in patients over 50 years. The percentage $H$ pylori seropositivity in coeliac disease did not differ from the percentage positivity observed in 250 similarly aged blood donors from the same geographic area (Leeds). Seropositivity in patients with dermatitis herpetiformis was not significantly different from the level of positivity observed in 98 age matched patients without dermatitis herpetiformis attending the same Edinburgh dermatology clinic. Only one patient with coeliac disease had positive intrinsic factor antibodies. $H$ pylori seropositivity in Edinburgh control subjects under 30 years of age $(41.9 \%)$ was significantly higher $(p<0.03)$ than in Leeds controls $(18 \%)$ of corresponding age. An increasing prevalence of $H$ pylori seropositivity with age in coeliac disease and dermatitis herpetiformis paralleled that of the control groups.

Conclusions: Gastritis in coeliac disease and dermatitis herpetiformis is largely caused by $H$ pylori infection at a level that is no different from that of the general population. Any increase in the prevalence of gastritis in these two diseases might be caused by lymphocytic gastritis rather than pernicious anaemia.

Both coeliac disease and dermatitis herpetiformis (which is frequently associated with coeliac disease) have been reported to be associated with abnormalities of gastric histology and gastric function. ${ }^{1-7}$ Changes of atrophic gastritis with an increased prevalence of parietal cell antibodies seem to be particularly common in several studies, ${ }^{2-4}$ although some have found little evidence to support this in coeliac disease ${ }^{8}$ and other abnormalities including those of lymphocytic gastritis have also been reported. ${ }^{910}$

Helicobacter pylori is now recognised to be a major aetiological factor in most patients with non-autoimmune chronic gastritis. ${ }^{11}$ In patients with pernicious anaemia, however, it is rare to find $H$ pylori infection on histological examination, suggesting that in this condition the gastric mucosa may be resistant to colonisation. ${ }^{12}{ }^{13}$ Seropositivity for $H$ pylor $i$ is rare in pernicious anaemia. ${ }^{13}$ In contrast, subjects with non-autoimmune gastritis have a high level of seropositivity for $H$ pylori, although the bacteria may be undetectable in biopsy specimens from patients with advanced atrophy of the acid secreting corpus mucosa. ${ }^{14}$

In this study we examined serum samples of patients with coeliac disease and dermatitis herpetiformis for $H$ pylori IgG antibodies and intrinsic factor antibodies in an attempt to establish the aetiology of the chronic gastritis reported in these patients.

\section{Methods}

Ninety nine patients with coeliac disease (mean (SD) age 40.9 (16.6), range 15-72 years) were studied. All had peripheral blood samples taken while undergoing jejunal biopsy. Twenty seven patients were untreated (mean age $39.3(16.3)$ years), with histological subtotal villous atrophy. Twenty five of these patients subsequently improved histologically once gluten had been excluded from the diet. Two have yet to be rebiopsied. Seventy two patients (mean age 41.1 (16.8) years) had been on a gluten free diet for at least six months at the time of investigation. Histologically, these subjects either had normal jejunal biopsy specimens or partial villous atrophy. Serum was stored at $-20^{\circ} \mathrm{C}$ until assayed. Control serum samples were obtained from 250 blood donors (age range 18-64 years) from the same geographic area as the patients with coeliac disease.

Fifty eight patients with dermatitis herpetiformis (mean age $51.5(16.7)$, range 14-79) were studied. All had blood samples taken while undergoing jejunal biopsy and serum was stored at $-70^{\circ} \mathrm{C}$. These patients come from a different regional location (Edinburgh) to the patients with coelic disease and blood donors (Leeds). As regional variations in $H$ pylori seropositivity are known to occur, ${ }^{1510}$ seropositivity in the patients with dermatitis herpetiformis was compared with that in 98 


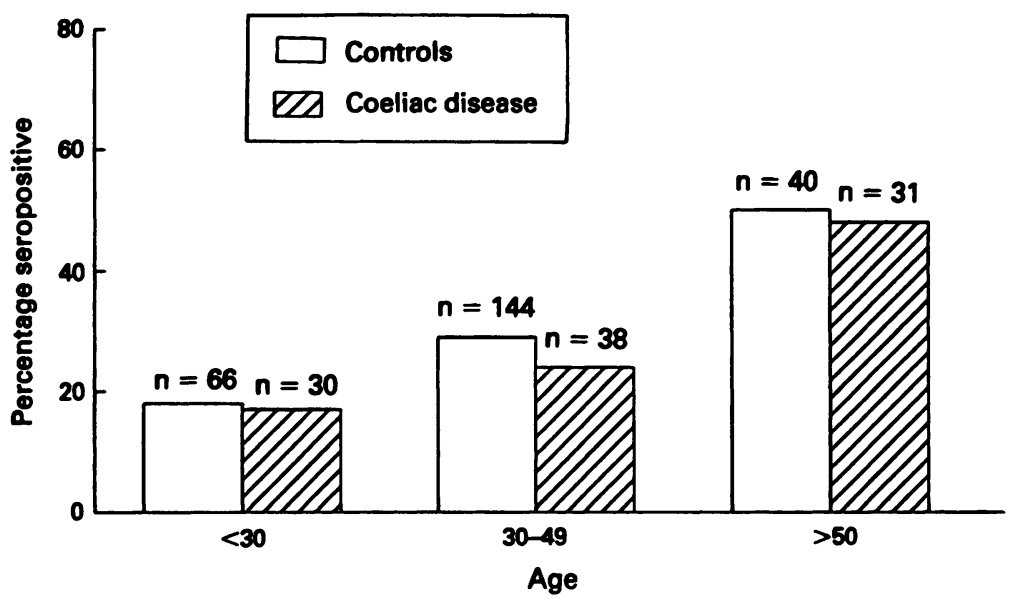

Figure 1 Percentage $H$ pylori seropositivity in patients with coeliac disease and blood donors in relation to age.

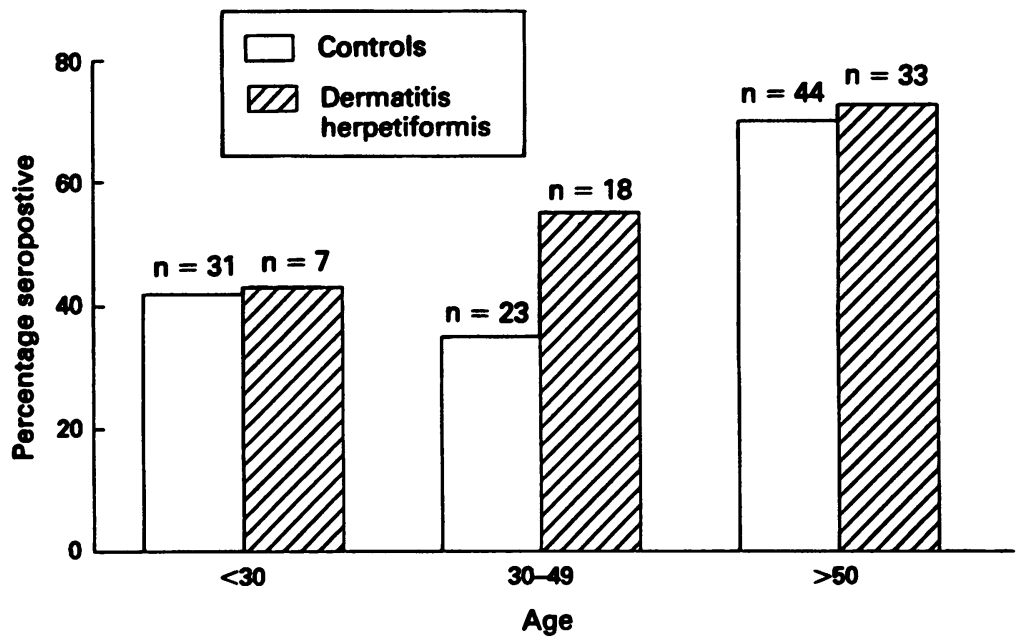

Figure 2 Percentage $H$ pylori seropositivity in patients with dermatitis herpetiformis and control subjects with other dermatological conditions in relation to age.

patients (mean age $45.3(20 \cdot 3)$, age range 15-95 years) attending the same dermatology clinic who had various inflammatory skin disorders but no history of dermatitis herpetiformis.

Serum samples were assayed for $H$ pylori IgG antibodies by ELISA, as previously described. ${ }^{1718}$ The antigen consisted of an ultracentrifuged sonicated preparation from one strain of $H$ pylori. Positive and negative controls were assayed on each plate. The cutoff for positivity was determined using serum from 116 patients with known $H$ pylori infection. Assay specificity and sensitivity were, respectively, $97 \%$ and $95 \%$. Previous studies have shown the specificity of the ELISA for $H$ pylori $^{18}$

Serum intrinsic factor blocking antibodies

$H$ pylori seropositivity in patients with untreated and treated coeliac disease

\begin{tabular}{|c|c|c|c|c|}
\hline \multirow[b]{3}{*}{ Age } & \multirow{2}{*}{\multicolumn{2}{|c|}{$\frac{\text { Untreated }}{H_{\text {pylori }}}$}} & \multirow{2}{*}{\multicolumn{2}{|c|}{$\frac{\text { Treated }}{H_{\text {pylori }}}$}} \\
\hline & & & & \\
\hline & Positive & Negative & Positive & Negative \\
\hline $\begin{array}{l}<30 \\
30-49 \\
>50\end{array}$ & $\begin{array}{l}4^{\star}(40 \%) \\
3(30 \%) \\
4(50 \%)\end{array}$ & $\begin{array}{l}6 \\
7 \\
4\end{array}$ & $\begin{array}{c}1(5 \%) \\
6(21 \%) \\
11(48 \%)\end{array}$ & $\begin{array}{l}19 \\
22 \\
12\end{array}$ \\
\hline
\end{tabular}

were assayed using a solid phase ${ }^{57} \mathrm{Co}$ radioimmunoassay (Diagnostic Products Corporation, Los Angeles, USA) according to the manufacturer's instructions.

Statistical analyses were carried out using the Yates's corrected $\chi^{2}$ and Fisher's exact tests, as appropriate.

\section{Results}

The percentage seropositivity for $H$ pylori in patients with coeliac disease and the blood donor controls in relation to age is shown in fig 1. Overall, $29 \%$ of patients with coeliac disease and $30 \%$ of the blood donors were $H$ pylori seropositive, with the percentage increasing with age in both groups. Forty eight per cent of patients with coeliac disease over the age of 50 were seropositive. The percentage seropositivity was not significantly different from that of the blood donor controls for any age group. $H$ pylori seropositivity was higher in patients with untreated coeliac disease (39\%) than in treated subjects $(25 \%)$ despite the group having similar mean ages. Under 30 years of age, seropositivity in untreated patients was $40 \%$ compared with $5 \%$ in subjects on a gluten free diet ( $p<0.04$; Fisher's exact test) (table), but no significant differences between treated and untreated patients were apparent in subjects between 30-49 and over 50 years (table).

The percentage seropositivity for $H$ pylor in patients with dermatitis herpetiformis and the control subjects with other dermatological conditions in relation to age is shown in fig 2 . Overall, $63.5 \%$ of patients with dermatitis herpetiformis and $53 \%$ of the control group were seropositive. Under 30 years of age, $41.9 \%$ of patients with dermatitis herpetiformis were seropositive, rising to $70 \%$ in those over 50 years of age. The percentage seropositivity in those under $30,30-49$, and over 50 years was not significantly different from the control group of patients from the same dermatology clinic, who showed similar high levels of seropositivity. The $41.9 \%$ seropositivity in Edinburgh controls under 30 years of age was significantly higher $(p<0.03)$ than Leeds controls of corresponding age $(18 \%)$.

Intrinsic factor blocking antibodies were found only in one patient with coeliac disease; this patient was seronegative for $H$ pylori. None of the patients with dermatitis herpetiformis had intrinsic factor antibodies.

\section{Discussion}

Gastric infection with $H$ pylori is now recognised as the aetiological agent in over $90 \%$ of cases of chronic gastritis. ${ }^{11}$ Because previous studies had suggested an increase in chronic gastritis in patients with coeliac disease and dermatitis herpetiformis, ${ }^{1-6}$ we expected to find a high prevalence of $H$ pylori among these groups. No increase in $H$ pylori seropositivity was evident in either coeliac disease or dermatitis herpetiformis, suggesting either that the prevalence of chronic gastritis is not higher in coeliac disease and dermatitis herpetiformis, or that $H$ pylori negative forms of chronic gastritis 
(such as autoimmune gastritis or lymphocytic gastritis) account for the higher proportion of gastritis among these patients.

The high prevalence of $H$ pylori infection in the general population makes selection of controls important. The increasing prevalence of $H$ pylori with increasing age in asymptomtic subjects is well recognised. ${ }^{19}$ More recently, geographical variations in prevalence within the same country have been documented ${ }^{16}$ and this is confirmed in our study where the prevalence of $H$ pylori was significantly higher in the control group from Edinburgh than from Leeds. The source of the control groups, however, differed. The importance of age and geographic factors in relation to gastritis may not have been recognised in previous studies which claimed an increased prevalence of gastritis in coeliac disease and dermatitis herpetiformis.

Previous studies, including acid secretion and autoantibody measurements, suggest that autoimmune gastritis with atrophy may be more common in patients with dermatitis herpetiformis. $^{2-6}$ However, using intrinsic factor antibodies as a marker for autoimmune gastritis, we found no evidence for this. As not all patients with autoimmune gastritis will have instrinsic factor antibodies, a proportion of patients with autoimmune mediated gastritis in coeliac disease and dermatitis herpetiformis may not have been detected. Impaired gastric acid secretion may also be found in Helicobacter associated gastritis, both in the early stages of the infection ${ }^{20}$ and in association with atrophic changes in the corpus mucosa in (presumably) longstanding infection. ${ }^{14}$ Thus $H$ pylori infection offers an alternative explanation for the hypochlorhydria previously observed in dermatitis herpetiformis and coeliac disease. It is interesting to speculate that the enhanced mucosal immunological responses in dermatitis herpetiformis ${ }^{2122}$ and coeliac disease $^{2324}$ may predispose infected subjects to more rapid development of atrophic gastritis and associated changes in gastric physiology.

Lymphocytic gastritis, a pattern of mucosal inflammation that is characterised by the presence of numerous intraepithelial $T$ cells, ${ }^{25}$ has recently been observed in patients with untreated coeliac disease. ${ }^{9}$ It is currently unclear whether this gastritis ${ }^{9}$ is a gastric manifestation of a gluten sensitive enteropathy analogous to the increase in intraepithelial lymphocyte density in the small intestine ${ }^{26}$ and in rectal mucosa as a response to the topical application of gluten. ${ }^{27}$ However, the introduction of a gluten free diet in patients with dermatitis herpetiformis did not change gastric morphology, acid secretion, serum gastrin concentrations or titres of parietal cell antibodies, ${ }^{28}$ suggesting that the gastric abnormalities were not related to gluten.

The increased $H$ pylori seropositivity in untreated coeliac patients under 30 years of age may be related to known defects in immunity of which one factor is hyposplenism. $^{29}$ As immune abnormalities are known to improve with a gluten free diet and improvement in splenic function can fol- low, ${ }^{29}{ }^{30}$ these changes would be expected to be more effective in younger subjects. It is intriguing to speculate whether, in this special situation, the decreased prevalence of seropositivity in young treated patients may follow resolution of infection. Whereas natural infection with $H$ pylori results in chronic gastritis, ${ }^{20}$ self limiting, acute infection has also been described. ${ }^{31}$

Existing data regarding the prevalence and type of gastritis in coeliac disease and dermatitis herpetiformis conflict. Our serological study shows that the prevalence of $H$ pylori infection is the same in these patients as controls and that autoimmune gastritis is uncommon. Gastric pathology in this group of patients therefore requires re-evaluation in the light of recent developments in our understanding of chronic gastritis.

We conclude that gastritis in coeliac disease and dermatitis herpetiformis is largely caused by $H$ pylori infection and that this is no different to the level in the general population. Any increase in the prevalence of gastritis in coeliac disease and dermatitis herpetiformis is unlikely to be due to pernicious anaemia, but could be partly accounted for by lymphocytic gastritis.

This study was carried out with financial support from the Yorkshire Regional Health Authority. We thank Dr D S Tompkins for providing the $H$ pylori strain used in the ELISA; Dr A Manning, Dr J Findlay, and the staff of the GastroDr A Manning, Dr J Findlay, and the staff of the Gastrocooperation; and Miss A Batty for technical assistance.

1 Hansky J, Shiner M. Gastric studies in idiopathic steatorrhea. Gastroenterology 1963;45:49-56.

2 Gillberg R, Kastrup W, Mobacken $H$, Stockbrugger $R$ Ahren $\mathrm{C}$. Gastric morphology and function in dermatitis herpetiformis and in coeliac disease. Scand $\mathcal{F}$ Gastroentero 1985;20:133-40.

3 O'Donoghue DP, Lancaster-Smith M, Johnson GD, Kumar PJ. Gastric lesion in dermatitis herpetiformis. Gut 1976;17:185-8.

4 Primignani M, Agape D, Ronchi G, et al. Gastric histology and function tests in Italian patients with dermatitis and function tests in Italian patients with dermatits

5 Kastrup W, Mobacken H, Stockbrugger R, Swolin B, Westin J. Malabsorption of vitamin B12 in dermatitis herpetiformis and its association with pernicious anaemia. Acta formis and its association with

6 Stockbrugger R, Kastrup W, Lundquist G, Mobacken H. Development of gastric dysfunction in dermatitis herpetiformis. Acta Derm Venereol (Stockh) 1978;158:343-48.

7 Gawkrodger DJ, McDonald C, O'Mahony S, Ferguson A Small intestinal function and dietary status in dermatitis herpetiformis. Gut 1991;32:377-82.

8 Lancaster-Smith MJ, Perrin J, Swarbrick ET, Wright JT. Coeliac disease and autoimmunity. Postgrad Med $\mathcal{F}$ 1974;50:45-8.

9 Wobler R, Owen D, DelBruno L, Appelman H, Freeman H. Lymphocytic gastritis in patients with celiac sprue or spruelike intestinal disease. Gastroenterology 1990; spruelike

10 Karttunen T, Niemela $S$. Lymphocytic gastritis and coeliac disease. F Clin Pathol 1990;43:436-7.

11 Dixon MF. Campylobacter pylori and chronic gastritis. In: Rathbone BJ, Heatley RV, eds. Campylobacter pylori and gastroduodenal disease. Oxford: Blackwell Scientific Publications, 1989:106-16.

12 Flejou JF, Bahame P, Smith AC, Stockbrugger RW, Rode J, Price AB. Pernicious anaemia and Campylobacter like organisms; is the gastric antrum resistant to colonisation? Gut 1989;30:60-4.

13 Fong TL, Dooley CP, Dehesa M, et al. Helicobacter pylori infection in pernicious anemia: a prospective controlled study. Gastroenterology 1991;100:328-32.

14 Karnes WE, Samloff IM, Siurala M, et al. Positive serum antibody and negative tissue staining for Helicobacter pylori in subjects with atrophic body gastritis. Gastroenpylori in subjects with atropt
terology 1991;101:167-74.

15 Megraud F, Brassens-Rabbe MP, Denis F, Belbouri A, Hoa DQ. Seroepidemiology of Campylobacter pylori infection in various populations. $f$ Clin Microbiol $1989 ; 27: 1870-3$. in various populations. $\mathcal{F}$ Clin Microbiol 1989;27:1870-3.
16 Hill MJ. H pylori carriage in patients with intestinal metaplasia and in endoscopical-proven normal controls. Rev Esp Enferm Digt 1990;78(suppl 1):83.

17 Crabtree JE, Mahony MJ, Taylor JD, Heatley RV, Littlewood JM, Tompkins DS. Immune responses to Helicobacter pylori in children with recurrent abdominal pain. F Clin Pathol 1991;4:768-71. 
18 Crabtree JE, Shallcross TM, Wyatt JI, et al. Mucosal humoral immune response to Helicobacter pylori in
patients with duodenitis. Dig Dis $S c i$ 1991;36:1266-73.

19 Kosunen TU, Hook J, Rauatelin HI, Myllyla G. Agedependent increase of Campylobacter pylori antibodies in dependent increase of Campylobacter pylori antibodies in

20 Sobala GM, Crabtree JE, Dixon MF, et al. Acute Helicobacter pylori infection: clinical features, local and cobacter pylori infection: clinical features, local and systemic immune response, gastric mucosal histology and gastric juice asco
$1991 ; 32: 1415-18$.

21 Valnes K, Brandtzaeg P, Elgio K, Stave R, Bekelin K, Faus $O$. Local immunoglobulin production is different in gastritis associated with dermatitis herpetiformis and simple gastritis. Gut 1987;28:1589-94.

22 O'Mahony S, Vestey JP, Ferguson A. Similarities in intestinal humoral immunity in dermatitis herpetiformis without enteropathy and in coeliac disease. Lancet 1990;335:1487-90.

23 Crabtree JE, Heatley RV, Losowsky MS. Immunoglobulin secretion by isolated intestinal lymphocytes: spontaneous production and T-cell regulation in normal small intestine and in patients with coeliac disease. Gut 1989; and in parie

24 O'Mahony S, Arranz E, Barton JR, Ferguson A. Dissociation between systemic and mucosal humoral responses in coeliac disease. Gut 1991;32:29-35.
25 Dixon MF, Wyatt JI, Burke DA, Rathbone BJ. Lymphocytic gastritis-relationship to Campylobacter infection. $\mathcal{f}$ Pathol 1988;154:125-32.

26 Howdle PD, Losowsky MS. Coeliac disease. In: Losowsky MS, Heatley RV, eds. Gut defences in clinical practice. MS, Heatley RV, eds. Gut defences in clinical pra

27 Loft DE, Marsh MN, Sandle GI, et al. Studies of intestinal lymphoid tissue. XII. Epithelial lymphocyte and mucosal responses to rectal gluten challenge in celiac sprue. responses to rectal gluten chath

28 Kastrup W, Andersson $H$, Gillberg $R$, Mobacken $H$, Stockbrugger R. Influence of gluten-free diet on the gastric condition in dermatitis herpetiformis. Scand $\mathcal{f}$ Gastroenterol 1985;20:39-45.

29 Howdle PD, Losowsky MS. The immunology of coeliac disease. Baillière's Clin Gastroenterol 1987;1:507-29.

30 Corazza GR, Frisoni M, Vaira D, Gasbarrini G. Effect of gluten-free diet on splenic hypofunction in adult coeliac disease. Gut 1983;24:228-30.

31 Marshall B, Armstrong J, McGechie D, Glancy R. Attempt to fulfill Koch's postulates for pyloric Campylobacter. to fulfill Koch's postulates 